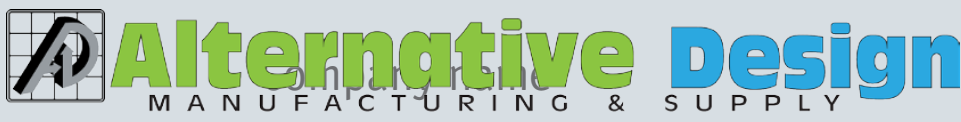

Proven Products. Creative Solutions.

\title{
Thermal neutral zone technology: the doorway to better research results
}

\author{
Michael Metze
}

The macroenvironment in an animal housing room can negatively affect an animal's microenvironment and, therefore, the results of laboratory research. Room temperature is one of the greatest environmental influences. The average temperature of a laboratory animal research facility is $20-24^{\circ} \mathrm{C}$, whereas mice are most comfortable in the range of $25.5-34^{\circ} \mathrm{C}$. Keeping rodent rooms in the normal temperature range for lab technicians can cause cold stress among the animals, which typically begins in the range of $18-25.5^{\circ} \mathrm{C}$. A temperature below $18^{\circ} \mathrm{C}$ will even compromise the growth rate of rodents ${ }^{1}$.

The thermal neutral zone is the range of temperatures in the immediate environment at which a healthy adult animal can maintain a normal body temperature without needing to use energy beyond its normal basal metabolic rate. All endotherms have a thermal neutral zone, and cold stress is a body's reaction to temperatures below the thermal neutral zone. When environmental temperature decreases below an animal's thermal neutral zone, its body's metabolic rate increases, causing thermogenesis in order to increase the body temperature. Rodents have a high thermal neutral zone, which means that, in a comfortable environment, they expend little energy on homeostasis - consuming calories and building up protective layers of fat-and more energy on other activities.

\section{Effects of temperature variation on research results}

Studies conducted by John M. David and colleagues at the University of California, Los Angeles ${ }^{2}$ have shown that chronic cold stress is present when rodents are housed at the temperatures recommended in the eighth edition of the Guide for the Care and Use of Laboratory Animals. This chronic cold stress causes greater energy expenditure and high metabolization of glucose reserves, especially in mice because they have a high surface area-to-volume ratio. As evidence of cold stress, David et al. found that mice housed in vivaria at routine temperatures had greater oxygen consumption and feed intake than they had at thermoneutral temperatures. Mice also displayed signs of impaired immune function and had elevated blood pressure and heart rate when housed in routine, colder temperatures as opposed to thermoneutral temperatures. For these reasons, research conducted at environmental temperatures that cause cold stress cannot be considered normal, and hence researchers can encounter serious consequences when attempting to translate findings into human medicine.

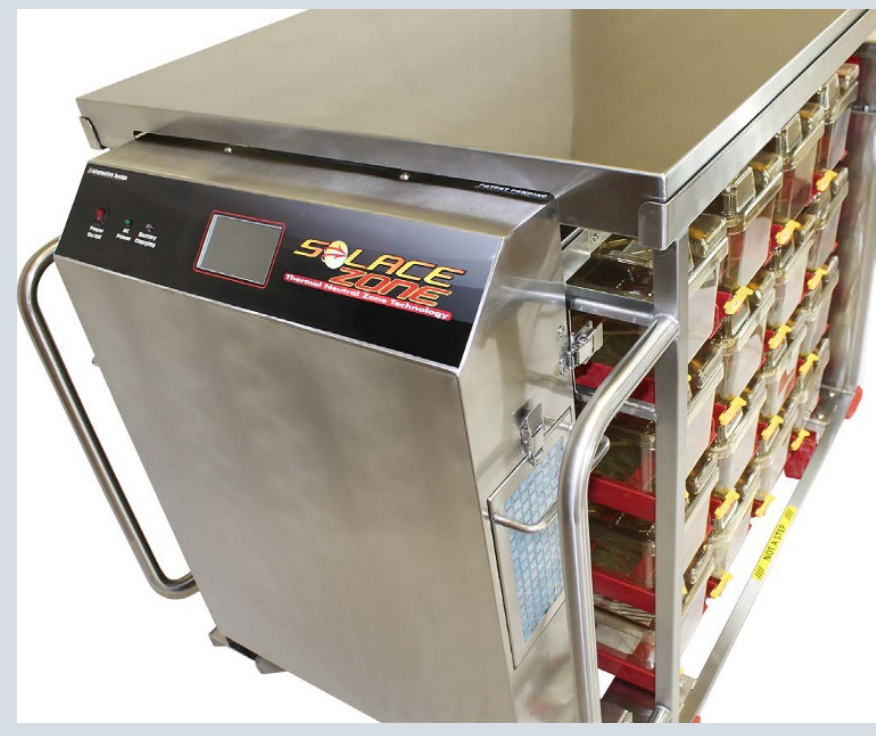

FIGURE 1 | Solace Zone Heated IVC 32-cage P.I. Mobile Unit.

\section{Cage-level temperature control}

New technology is now available that eliminates temperaturerelated problems at the microenvironmental level by enabling researchers to control temperatures at the cage level. By contrast, this reduces discomfort to those that work with the animals, who prefer a lower macroenvironmental temperature.

The Solace Zone Heated IVC 32-Cage P.I. Mobile Unit from Alternative Design (Fig. 1) uses patent-pending technology to provide heated and HEPA-filtered, ventilated air. This is the only heated individually ventilated cage (IVC) currently available in the laboratory animal research industry. The mobile unit creates a balanced airflow and zone-controlled temperature within each IVC, which helps to alleviate cold stress in rodent research models and creates a warm, comforting environment for postoperative recovery.

\section{Feature-rich, cutting-edge equipment}

The Solace Zone Heated IVC unit is constructed of quality 304 stainless steel with a removable top shelf that doubles as a work surface for lab technicians. This mobile unit rests on 5-inch casters, two of which have brakes. The entire Solace Zone unit can be autoclaved, with the exception of two parts: the air handling unit and power channels. This unit comes with Alternative Design's new 'stacks-in-place' feature that allows stacks of cages to be left on the frame during autoclaving. 


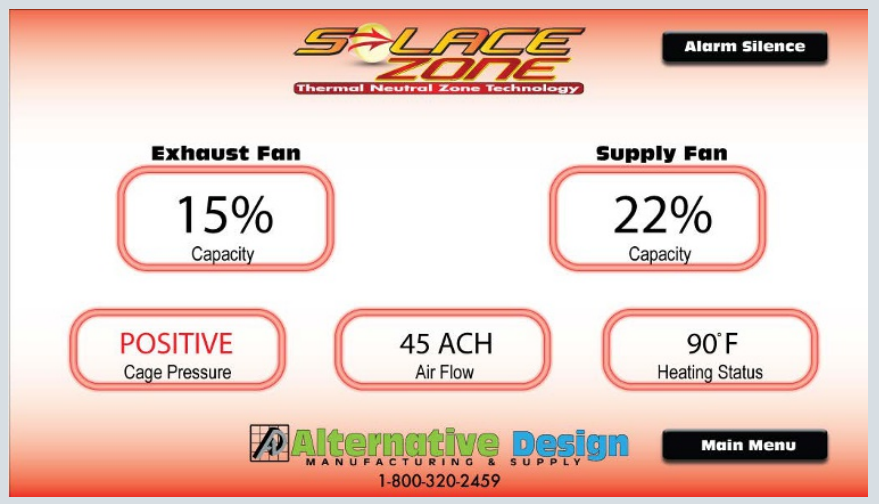

FIGURE 2 | Touchscreen controls for the air handling unit of the Solace Zone heated IVC unit.

The air temperature in each IVC can be adjusted using touchscreen controls on the LED display of the air handling unit (Fig. 2). The temperature can be increased or decreased in increments of $5^{\circ} \mathrm{F}\left(2.8^{\circ} \mathrm{C}\right)$. This unit also allows for the air change rate to be set to one of three levels: 45,60 or 80 air changes per hour. This heated IVC unit also comes standard with two on-board battery settings: a transport mode and an emergency mode wherein the battery lasts for up to 24 hours, in case the building undergoes a power failure. The Solace Zone Heated IVC P.I. Mobile Unit holds up to 32 'Gentle-Air'-style cages, with 16 cages per side.

Alternative Design engineered this new technology for the benefit of all facilities conducting mouse research. Improving the reliability of research results is critical to the future success of laboratory animal science.

\section{Company profile}

For nearly 30 years, Alternative Design has been a leading provider of animal housing solutions to the laboratory animal research community. The Modular Animal Caging System ${ }^{\circledR}$, or M.A.C.S. ${ }^{\circledR}$, is the only modular IVC in the industry, designed to increase cage density in animal rooms, improve workflow and create more space within a vivarium. The company is also known for producing a variety of other innovative products like the Solace Zone heated IVC, the Halcyon Air tower, modular large animal runs, and quality material handling and storage equipment including bulk trucks, utility carts and shelf racks. The company has a strong reputation for quality construction and customer service, including an industry-leading 5 -year warranty on all stainless steel fabricated products. For more information, please call 1-800-320-2459 (US and Canada) or visit the website at http://www.alternativedesign.com.

1. Moberg, G.P. Biological response to stress: implications for animal welfare. in Biology of Animal Stress: Implications for Animal Welfare. (eds. Moberg, G.P. \& Mench, J.A.) 1-22 (CAB International, Wallingford, UK, 2000).

2. David, J.M., Chatziioannou, A.F., Taschereau, R., Wang H. \& Stout, D.B. The hidden cost of housing practices: using noninvasive imaging to quantify the metabolic demands of chronic cold stress of laboratory mice. Comp. Med. 63, 386-391 (2013).

This article was submitted to Lab Animal by a commercial organization and has not been peer-reviewed. Lab Animal takes no responsibility for the accuracy or relevancy of the information provided therein. 